\title{
Burn Out
}

Burn out; I was thinking about this the other day when I read that Zinidane retired from international competition. He remains a great "football" player, but he decided to cut back a little. He decided that he could continue to play for his club team, but not continue the rigors of the international "friendlies" and other competition. Perhaps his income will come down a little, but I can see his point. When I decided to step down as Editor in Chief of Seminars in Interventional Radiology, I felt the same way. Is Zinidane burnt out? Am I? Sometimes I wonder about it.

I have always thought that it is difficult to perform interventional procedures all the time for one's whole career. I could list several well-known interventional radiologists who have turned to other activities, and are no longer doing procedures. Yet, there are plenty of other interventional radiologists who are still out there grinding away, whether in private practice or in academic centers. Or so I think! Perhaps some of them are doing both interventional and diagnostic radiology.

In my Division at Massachusetts General Hospital, which performs both diagnostic and interventional procedures, there are many staff members who tell me that they could not be the main person organizing and supervising 20 to 30 procedures per day more than 2 days a week. I have heard this from radiologists outside our Division as well. Yet I know several surgeons who do procedures their whole professional life. Perhaps the surgeons get that personal feedback that we don't often get or didn't use to get, and that is what keeps them going. I also know that some of my most satisfying days end after spending days doing a variety of complicated and uncomplicated procedures that not only help patients, but also solve a lot of clinical problems.

Am I observing something and concluding something that is not really true? Am I over reacting to the few comments that I have heard from people in my group, and other radiologists whom I have met over the years? Do I just hang around with radiologists over 50 who are all winding down their careers? I do know that the pressures to do things today and to get things done quickly are present now more than ever.

In a way, we are the victims of our own successjust as Zinidane is. Our specialty is still growing. It is a necessity for any hospital that prides itself on giving good clinical care to have a radiology department that provides excellent interventional radiology service. The expectations for us are high and demanding. We are also in the "service" business. We can talk all we want about setting up our own service and having our own patients, but the majority of what we do is still work as "consultants," taking care of other people's patients. That in itself makes interventional radiology a very demanding field. It will change somewhat over the next few years, but not completely.

As someone who lives in Boston, I compare this phenomenon (stress, demands, burn out, etc.) to playing for the Red Sox. The fans' expectations are high; the media and the fans are very demanding: we won't settle for mediocrity and we whine about everything (like some referring physicians). No wonder playing for the Red Sox is so difficult. Does anyone really want to play for the Red Sox? Would you want to subject yourself to "sports talk" abuse and expectations every day during the season? No wonder those of us who do interventional procedures feel downtrodden sometimes. Sometimes doing a interventional procedure is like playing for the Red Sox.

An interventional procedure can be the most demanding, most difficult, most frustrating and definitely MOST SATISFYING THING YOU DO ALL DAY. The Red Sox players that can handle it will tell you that there is nothing in baseball like playing in Boston. Nothing is as exhilarating or exciting; nothing gives as much satisfaction. Ask the players who leave.

This is interventional radiology; it is tough and it is demanding. I suppose you can burn out on it, but it is incredibly satisfying, exhilarating, and it is fun. So at the end of the day when things are difficult, think about the good things. In addition, we learn something from the patients we treat that many ball players could also benefit from. Many of the patients that I have dealt with have taught me about dignity and composure under horrible situations, courage under severe distress, the importance of family-and have been incredibly thankful for the smallest thing I do, even a thoracentesis.

It is all there in front of us-we need to understand it, embrace it, and not let the difficult aspects of our profession get us down.

Peter R. Mueller, M.D. Editor in Chief ${ }^{1}$

Interventional Radiology in the GI Tract; Editor in Chief, Peter R. Mueller, M.D.; Guest Editor, Michael J. Lee, M.D. Seminars in Interventional Radiology, volume 21, number 3, 2004. ${ }^{1}$ Division Head, Abdominal Imaging and Intervention, Department of Radiology, Massachusetts General Hospital, Boston, Massachusetts. Copyright (C) 2004 by Thieme Medical Publishers, Inc., 333 Seventh Avenue, New York, NY 10001, USA. Tel: +1(212) 584-4662. 0739-9529,p;2004,21,03,141,141,ftx,en;sir00254a. 